\title{
The role of subtotal and total gastrectomy in the treatment of gastric cancer
}

\author{
Július PALAJ ${ }^{1, \star}$, Štefan KEČKÉŠ ${ }^{2,3}$, Iveta WACZULÍKOVÁ ${ }^{4}$, Vítězslav MAREK ${ }^{1}$, Daniel DYTTERT ${ }^{1}$, Martin SABOL ${ }^{1}$, Štefan DURDÍK ${ }^{1,3}$
}

${ }^{1}$ Department of Oncological Surgery, St. Elizabeth Cancer Institute, Slovak Republic and Faculty of Medicine in Bratislava of the Comenius University, Bratislava, Slovakia; ${ }^{2}$ Department of Immunodiagnostics, St. Elizabeth Cancer Institute, Bratislava, Slovakia; ${ }^{3}$ St. Elizabeth University of Health and Social Sciences, Bratislava, Slovakia; ${ }^{4}$ Department of Nuclear Physics and Biophysics, Comenius University, Faculty of Mathematics, Physics and Informatics, Bratislava, Slovakia

${ }^{*}$ Correspondence: julius.palaj@ousa.sk

Received September 23, 2020 / Accepted December 20, 2020

\begin{abstract}
The optimal procedure for the lower third gastric adenocarcinoma is still an open question. We performed an analysis of the long-term survival of patients after subtotal (SG) or total gastrectomy (TG) on 164 enrolled patients. Bivariate and multivariable analyses were performed in order to identify characteristics associated with long-term survival. Survival was significantly affected by the number of positive lymph nodes (LN). Patients who have undergone TG had a higher number of total removed LN. The adjusted hazard ratio for the TG group suggests a partial superiority of TG over SG for patients with curative intent. Our data support the importance of extended LN dissection.
\end{abstract}

Key words: gastric cancer, total gastrectomy, subtotal gastrectomy, lymphadenectomy

More than a century has passed since Billroth's first radical resection in 1891 and the first total gastrectomy (TG) carried out by Schlatter in 1897 . Nevertheless, the choice of optimal procedure for the lower (distal) third gastric adenocarcinoma is still an open question [1]. TG was associated with high mortality in the past, therefore, up to 1938, only 27 TGs were documented according to Mayo Clinic [2]. In the 1940s Scott and Longmire published a study where perioperative mortality after TG has been successfully reduced to 9.5\% [3]. Longmire summarized the results of 15 studies from the $1940 \mathrm{~s}$ to 70 s, TG was performed in $6.5-48.8 \%$ of all resections [3]. As indicated already in the paper by Longmire, the concept of Japanese surgeons was based on the idea that extensive lymphadenectomy would be ultimately more beneficial than radical gastric resection. According to this concept, it is considered crucial to remove locoregional lymph nodes (LNs) in order to prevent metastasis and thus improve survival [4]. At that time, most patients with gastric cancer (GC) in Europe were diagnosed at an advanced stage, therefore, the en principle TG, i.e., total gastrectomy with $\mathrm{LN}$ dissection was the preferred surgical treatment to ensure better long-term survival. Several renowned surgeons were the representatives of this view [5] and one of the reasons that supported the concept was the above-mentioned higher prevalence of large tumors and LN involvement. Nevertheless, the assumption that the long-term survival could be influenced by the en principle TG-driven choice of procedure was not confirmed and 5-year survival in the 1970s was achieved in only $20 \%$ of GC patients $[3,6]$. In contrast with en principle $T G$ concept, two multicentric prospective randomized studies published by Gouzi et al. in 1989 and Bozzeti et al. in 1999, showed similar survival rates for subtotal gastrectomy (SG) and TG $[4,7,8]$. From the 1980 s, only a few retrospective studies have been published and all have failed to prove the superiority and overall survival benefit from TG. Thus, the extent of surgery remains among surgeons subject to debate. Recent studies have shown that for patients with middle-third GC, distal SG shortens the operation duration and postoperative hospital stay and reduces postoperative complications [9]. Some authors assume that SG may be beneficial and preferable for proximal GC $[10,11]$. Goto et al. reported noninferiority of SG for remnant GC at stage IA disease [12]. The indication of TG or SG is nowadays a very complex process taking into account the stage of disease, location and biology of the tumor, comorbidity of the patient, expected quality of life, and also the patient's needs and preferences $[13,14]$.

Over the past decade, we have perceived in our Department of Surgery that patients who underwent potentially curative TG might have better survival rates in comparison to those with SG. Therefore, our goal was to explore our clinical experience and perform an adjusted analysis of the long-term survival of patients after radical resection of GC by either procedure, taking into account differences in prognostic factors or baseline characteristics between TG and SG groups 
that might influence the outcome with focusing on the effect of the total number of LNs removed during the resection and the number of positive LNs.

\section{Patients and methods}

All records of patients who underwent radical resection for GC in the range of SG or TG between January 1, 2007 and December 31,2018, and entered a routine follow-up protocol, were retrieved from the institutional database and screened for eligibility. The inclusion criteria for this study were as follows: 1) age above 20 years; 2 ) history of radical SG or TG, and 3) histologically confirmed GC. Exclusion criteria: gastrointestinal stromal tumors, neuroendocrine neoplasms, and lymphomas. Finally, a total of 164 patients with GC were included in the study. The clinicopathological stage of all patients was classified according to TNM classi-

Table 1. Clinical and laboratory characteristics of 164 patients with gastric cancer treated between January 2007 and January 2019 grouped by the primary outcome.

\begin{tabular}{|c|c|c|c|c|}
\hline $\begin{array}{l}\text { Patients' } \\
\text { characteristics }\end{array}$ & $\begin{array}{c}\text { Total } \\
\mathrm{n}=164\end{array}$ & $\begin{array}{l}\text { Dead } \\
\mathrm{n}=72\end{array}$ & $\begin{array}{c}\text { Survived } \\
\mathrm{n}=92\end{array}$ & p-value \\
\hline $\begin{array}{l}\text { Age (years) } \\
\text { Mean } \pm \text { SD }\end{array}$ & $63.9 \pm 10.88$ & $64.3 \pm 10.25$ & $63.6 \pm 11.40$ & 0.9721 \\
\hline \multicolumn{5}{|l|}{ Sex } \\
\hline Male & 97 & 41 & 56 & \multirow[t]{2}{*}{0.6118} \\
\hline Female & 67 & 31 & 36 & \\
\hline \multicolumn{5}{|l|}{ NACT } \\
\hline Yes & 129 & 59 & 70 & \multirow{3}{*}{0.3329} \\
\hline No & 33 & 12 & 21 & \\
\hline Not applied & 2 & 1 & 1 & \\
\hline \multicolumn{5}{|l|}{ Surgery } \\
\hline TG & 89 & 40 & 49 & \multirow[t]{2}{*}{0.5426} \\
\hline SG & 75 & 32 & 43 & \\
\hline \multicolumn{5}{|l|}{ Histology } \\
\hline Diffuse & 87 & 43 & 44 & \multirow{3}{*}{$0.0304^{\star}$} \\
\hline Mixed & 13 & 3 & 10 & \\
\hline Intestinal & 64 & 26 & 38 & \\
\hline \multicolumn{5}{|l|}{ Positive LN } \\
\hline Yes & 107 & 57 & 50 & \multirow[t]{2}{*}{0.0009} \\
\hline No & 57 & 15 & 42 & \\
\hline \multicolumn{5}{|l|}{ Total LN removed } \\
\hline $\begin{array}{l}\text { Median } \\
\text { (Q1-Q3) }\end{array}$ & $\begin{array}{c}22 \\
(14.5-31.5)\end{array}$ & $\begin{array}{c}21 \\
(13.5-29)\end{array}$ & $\begin{array}{c}22 \\
(15-32)\end{array}$ & 0.4663 \\
\hline \multicolumn{5}{|c|}{ Positive LN/Total LN } \\
\hline $\begin{array}{l}\text { Median } \\
\text { (Q1-Q3) }\end{array}$ & $\begin{array}{c}0.098 \\
(0-0.39)\end{array}$ & $\begin{array}{c}0.243 \\
(0.07-0.6)\end{array}$ & $\begin{array}{c}0.038 \\
(0-0.23)\end{array}$ & $<0.0001$ \\
\hline \multicolumn{5}{|l|}{ T status } \\
\hline $\mathrm{T} 1$ (one in situ) & 29 & 6 & 23 & \multirow{4}{*}{0.0109} \\
\hline $\mathrm{T} 2$ & 19 & 8 & 11 & \\
\hline $\mathrm{T} 3$ & 50 & 23 & 27 & \\
\hline $\mathrm{T} 4$ & 66 & 35 & 31 & \\
\hline
\end{tabular}

Note: ${ }^{*}$ significance for intestinal or mixed type versus diffuse type; NACT neoadjuvant chemotherapy fication 2010 [15]. The primary outcome was the overall survival of patients after TG and SG adjusted for the effects of covariates - the number of LNs removed and LN involvement. The Cox regression procedure was used for modeling the time at which the event (death from any cause occurring during the follow-up) or censoring occurred based upon the values of the covariates [16]. Survivors and patients censored for loss to follow up (e.g., transfer of care) were considered beginning on the day of surgery and continuing until the last recorded visit or until December 31, 2018 (the end of study).

This study was conducted in accordance with the ethical principles set forth in the Declaration of Helsinki and approved by the Institutional Review Board. Statistical analyses were performed using Microsoft Office Excel 2010 (Microsoft Corporation) and StatsDirect ${ }^{\circledR}$ 3.2.7 (StatsDirect Ltd., Cheshire, UK).

\section{Results}

From a total of 164 patients with GC, 97 (59.1\%) were males and 67 (40.9\%) were females, with male to female ratio reflecting those reported by the created web portal about tumor epidemiology in the Czech Republic, which reflects the epidemiological situation in our country as well [https://portal.med.muni.cz/article-584-epidemiologyof-malignant-tumours-in-the-czech-republic.html]. TG was performed in 89 patients with an average age of 62, the average number of removed LNs was 24.5. Patients with negative LNs were 26 (29.2\%). Positive LNs were found in $63(70.8 \%)$ patients with the average number of positive LNs 9.3. 75 patients underwent $S G$ with an average age of 66 , the average number of removed LNs was 20.3, patients without LN involvement were 31 (41.3\%). Metastases in LNs were detected in $44(58.7 \%)$ patients with an average number of positive LNs of 6.6 .

Bivariate analysis. Patients' demographic and clinicopathological characteristics grouped by the outcome are summarized in Table 1. Bivariate analysis of overall survival rate within the subgroups by the type of surgery, histology, $\mathrm{LN}$ involvement, and T status is presented in Figures 1A-1D. Non-significantly worse survival in the TG group (Figure 1A) was reverted on the multivariable analysis (Table 2) after adjustment on covariates significantly associated with prognosis in bivariate analysis.

The distribution of the number of LNs removed during surgery is shown in Figure 2. The mean LN removed in the TG subgroup was not significantly different between dead $(24.9$, median $22 ; \mathrm{n}=40)$ and survived patients on bivariate analysis $(24.2$, median $25 ; \mathrm{n}=49 ; \mathrm{p}=0.784)$. The difference between means for dead and survived patients in the SG subgroup was more pronounced, although still not statistically significant $(18.5$, median $17.5 ; \mathrm{n}=32$, vs. 21.7 , median 20 ; $\mathrm{n}=43 ; \mathrm{p}=0.187$ ). However, the mean $\mathrm{LN}$ removed in the SG subgroup was significantly lower than that in the TG subgroup (20.3 vs. $24.5 ; \mathrm{p}=0.011$ ). At the same time, we have found a 
A

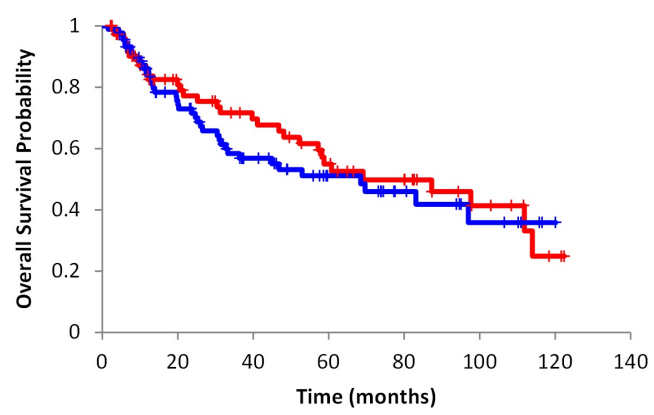

C

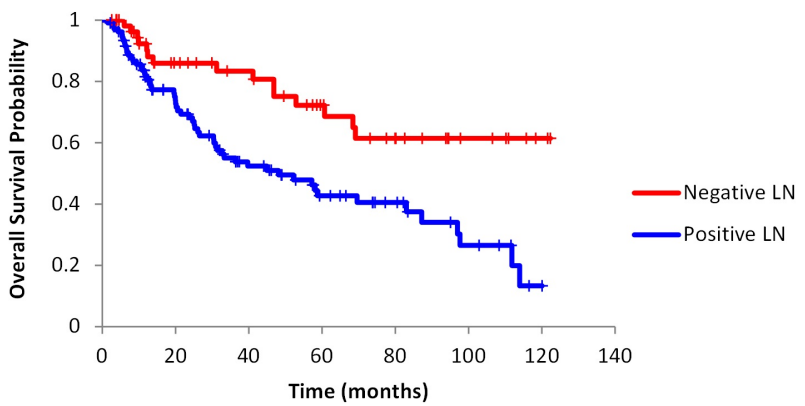

B

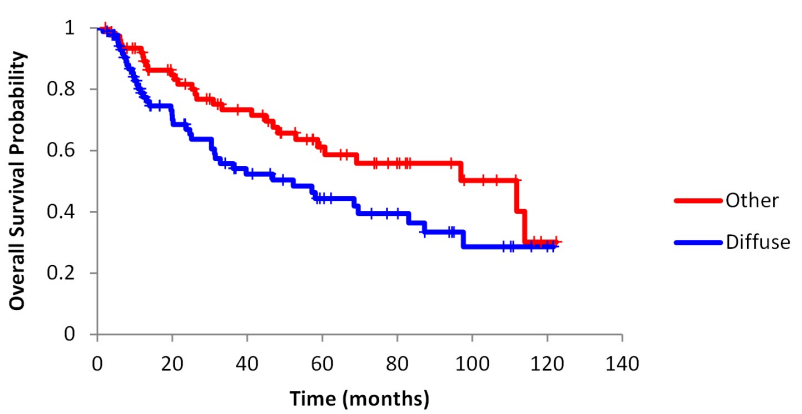

D

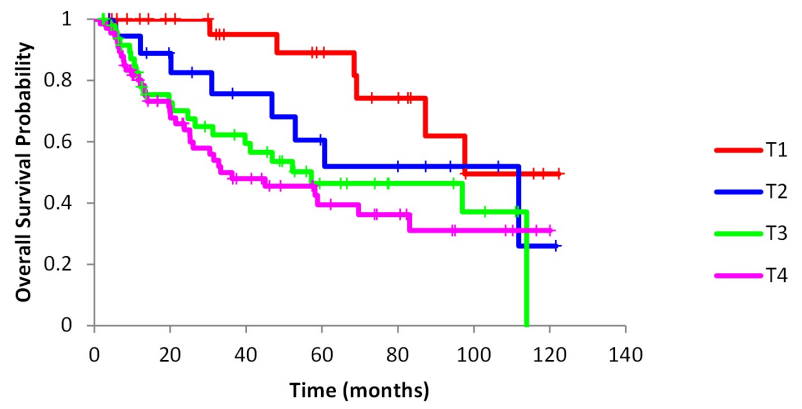

Figure 1. Kaplan-Meier curves for OS in patients with GC, grouped by A) type of surgery (log rank test: p=0.543, non-significant), B) histological type (diffuse vs. other, $\mathrm{p}=\mathbf{0 . 0 3 3}), \mathrm{C})$ lymph node status (log rank test: $\mathrm{p}=\mathbf{0 . 0 0 1})$, and $\mathrm{D}) \mathrm{T}$ staging (overall log rank test: $\mathrm{p}=\mathbf{0 . 0 1 1}$ ).

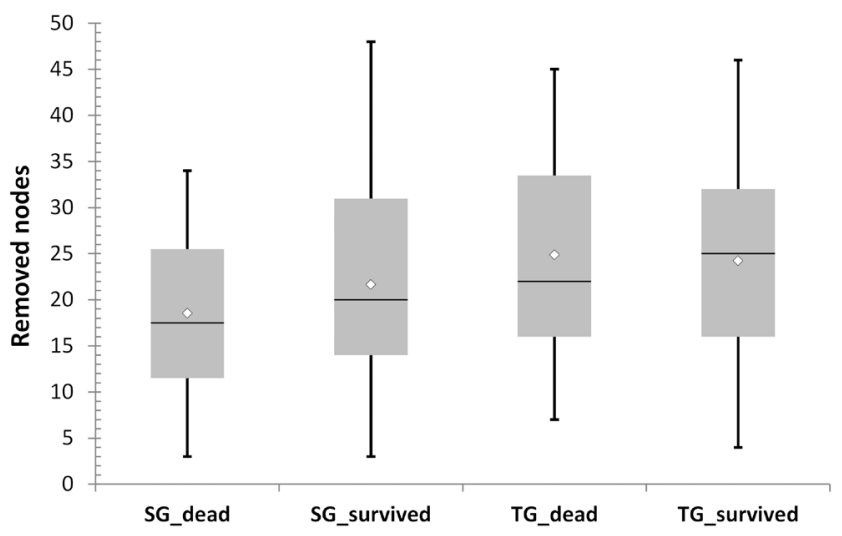

Figure 2. Box-plots of the number of removed lymphatic nodes, grouped by the type of surgery and the outcome. The box shows the interquartile range, the $\mathrm{T}$-bars represent the highest and the lowest values, the horizontal line in the middle is the median, and the diamond represents the mean.

moderate, but significant positive correlation between the numbers of positive $\mathrm{LN}$ and $\mathrm{LN}$ removed ( $\mathrm{r}=0.340 ; \mathrm{p}<0.001)$. Since the number of LNs removed was unambiguously linked to the type of surgery, this variable might act as a potential confounder distorting the relationship between the exposure (the treatment groups) and the outcome (the distribution of survival times). Therefore, we included this characteristic in the multivariable Cox regression model.
Table 2. Multivariable Cox regression analysis of factors associated with overall survival in patients with gastric cancer.

\begin{tabular}{lcccc}
\hline Variable & b & p-value & HR & 95\% CI \\
\hline $\begin{array}{l}\text { Type of surgery: TG (coded } \\
\text { as 1) vs. SG (coded as 0) }\end{array}$ & -0.2038 & 0.4257 & 0.8157 & $0.494-1.347$ \\
$\begin{array}{l}\text { Histology: diffuse (coded as 1) } \\
\text { vs. other (coded as 0) }\end{array}$ & 0.3609 & 0.1505 & 1.435 & $0.877-2.346$ \\
$\begin{array}{l}\text { Removed nodes } \\
\text { (per one node increase) }\end{array}$ & -0.0111 & 0.4053 & 0.989 & $0.963-1.015$ \\
$\begin{array}{l}\text { Positive nodes } \\
\text { (per one node increase) }\end{array}$ & 0.0662 & 0.00003 & 1.069 & $1.036-1.102$ \\
T1 status & & & & reference \\
T2 status & 0.7832 & 0.1490 & 2.189 & $0.755-6.340$ \\
T3 status & 0.8999 & 0.0595 & 2.459 & $0.965-6.269$ \\
T4 status & 1.0109 & 0.0301 & 2.748 & $1.102-6.850$ \\
\hline
\end{tabular}

Note: the likelihood $\chi^{2}$ test statistic was 33.715 and corresponding p-value $<<0.001$. Abbreviations: b-regression coefficients; HR-hazard ratio; 95\% CI95\% confidence interval; P-probability; TG-total gastrectomy; SG-subtotal gastrectomy

Multivariable analysis. We used a standard Cox proportional hazards regression model to test the impact of the type of surgery on survival in addition to other covariates selected from the clinicopathological features known to affect gastric cancer patients' survival. Results of fitting the Cox model to the data and testing the selected predictors for a significant effect on survival-time are presented in Table 2. In the multivariable modeling of time-to-death, positive LN and more 
advanced tumor stage variables remained statistically significant terms, and have kept their statistically and/or clinically important contribution to survival. From the adjusted HR below one, it follows that the survival outcomes were more beneficial for the TG group in comparison with the SG. The same holds for the number of removed LNs with higher numbers improving survival outcomes.

The multiple regression analysis did not confirm the superiority of one procedure to another regarding their effects on survival. However, with standard hypothesis testing we cannot claim the equivalence between the two surgical approaches (i.e., confirm the null hypothesis). Therefore, based on the estimated hazard, there might still be the possibility of better survival for the TG group. Our results suggest that our study might have been underpowered to detect a significant effect of either approach, this controversial topic can only be clarified by more efficiently designed clinical trials.

\section{Discussion}

The extent of gastric resection for GC is still a discussed topic, also due to a relatively low percentage of patients with 5-year survival in the Western world. The proportion of diffuse carcinomas in different geographic locations may also affect decision-making on the extent of the procedure. Literature data suggest that TG does not improve survival in patients with middle- and distal third GC, hence SG is currently the preferred procedure [17-19]. Nevertheless, TG is carried out in the Western world in relatively high numbers. In a meta-analysis of 6 studies, Kong reported comparable survival rates between patients treated with TG and those treated with SG [18]. A higher percentage of complications and fistulas were detected in TG patients, which, however, can be explained by the fact that the meta-analysis included some older studies, while safer more modern procedures are currently available. In Bozzeti's study [8], there was a higher number of splenectomies in patients undergoing TG, which could also affect morbidity. Newer and more modern equipment is currently available, as well as new surgical procedures that reduce operative time, blood loss, surgical shock, and forced TG. All these facts lead to lower overall perioperative morbidity and mortality. Thus, at present, perioperative mortality was reduced in specialized high-volume centers to $3 \%$ [20-22]. At the time of the introduction of laparoscopic surgery of GC, a higher proportion of patients undergoing SG surgery has been reported [23]. Even though according to the latest research, SGs are performed in the vast majority of the cases [13], however, Gertsen et al. reported $42.2 \%$ of performed TGs [24].

In our study, TG was the dominant modality performed in $54.2 \%$ of the cases. We examined retrospectively the differences in long-term overall survival in both groups of radically operated patients. In the TG group, there were more patients with advanced disease and with a diffuse subtype of carcinoma. However, long-term survival adjusted for histology, the number of removed and positive nodes, and for $\mathrm{T}$ status, was better in patients undergoing TG, even if the decrease in the instantaneous hazard rate did not achieve statistical significance (Table 2). Mortality and morbidity in both groups, TG and SG, were comparable. Several patients underwent multivisceral resection along with TG. Despite this fact, 30-day mortality was not present and 90 days mortality was comparable to other high-volume centers mentioned above ( 1 case in the TG group $-1.1 \%, 2$ cases in the SG group - 2.7\%). Our analysis has shown that the higher number of removed LNs independently improves the longterm survival in both groups. On the other hand, the higher number of positive LNs and the histological type (diffuse type) both worsen the prognosis. These results are in line with the significant multicentric East Asian study conducted by Woo (Yonsei GC Prognosis Prediction Model) [25]. HRs for the number of retrieved LN are almost the same $(0.986$ vs. 0.989 ). The HR value of 0.895 per each 10 removed LNs can easily be calculated using the respective regression coefficient $(-0.0111)$. Results of Woo suggest the superiority of SG, but he included also palliative patients, which could have had an impact on the result. Ju prefers the TG for larger, more aggressive tumors with higher stage [19].

In Western countries, more advanced stages of GC are diagnosed compared to Asian countries. Similarly, the patients in our study have a higher proportion of T3 and T4 status as well as a higher proportion of the invasion into surrounding organs and a corresponding higher number of TGs. Probably the most important finding of our study is that the total number removed and positive LNs are clinically important factors influencing long-term survival. This fact can explain to some extent, why the results of TG and SG are comparable in general. The main goal of surgery in GC patients should not be only the maximum extent of gastric resection, but also the effort to prevent $\mathrm{LN}$ involvement. The higher number of removed LNs provides a presumption that there will be also removed positive LNs, which may be not revealed by histopathologic examination.

In our study, patients who have undergone TG had a higher number of total removed LNs. Even if this study was insufficient to prove the superiority of one procedure to another, it suggests the superiority of TG over patients with curative intent. Our data support the view of the importance of extended lymph node dissection.

Acknowledgments: The study was partially supported by the grant KEGA 041UK-4/2020.

\section{References}

[1] WELEDJI EP. The principles of the surgical management of gastric cancer. Int J Surg Oncol (N Y) 2017; 2: e11. https:// doi.org/10.1097/IJ9.0000000000000011 
[2] JOLL CA, ADLER DI. Long survival after total gastrectomy. Br Med J 1942; 2: 632-635. https://doi.org/10.1136/ bmj.2.4273.632

[3] LONGMIRE WP. Gastric carcinoma: is radical gastrectomy worth while? Ann R Coll Surg Engl 1980; 62: 25-30.

[4] PEETERS K., editor. Quality assurance in surgical oncology. Rotterdam: K.C.M.J. Peeters 2007, 2007.

[5] LORTAT-JACOB J, GIULI R, ESTENNE B, CLOT P. Value of total gastrectomy for treatment of cancers of the stomach. Study of 482 radical operations. Chirurgie 1975; 101: 59-67.

[6] MCNEER G, BOWDEN L, BOONER RJ, MCPEAK CJ. Elective total gastrectomy for cancer of the stomach: end results. Ann Surg 1974; 180: 252-256. https://doi. org/10.1097/00000658-197408000-00022

[7] GOUZI JL, HUGUIER M, FAGNIEZ PL, LAUNOIS B, FLAMANT Y et al. Total versus subtotal gastrectomy for adenocarcinoma of the gastric antrum. A French prospective controlled study. Ann Surg 1989; 209: 162-166. https://doi. org/10.1097/00000658-198902000-00005

[8] BOZZETTI F, MARUBINI E, BONFANTI G, MICELI R, PIANO C et al. Subtotal versus total gastrectomy for gastric cancer: five-year survival rates in a multicenter randomized Italian trial. Italian Gastrointestinal Tumor Study Group. Ann Surg 1999; 230: 170-178. https://doi.org/10.1097/00000658199908000-00006

[9] JI X, YAN Y, BU ZD, LI ZY, WU AW et al. The optimal extent of gastrectomy for middle-third gastric cancer: Distal subtotal gastrectomy is superior to total gastrectomy in short-term effect without sacrificing long-term survival. BMC Cancer 2017; 17: 345. https://doi.org/10.1186/s12885-017-3343-0

[10] CHEN Y, ZHAO L, HU S, ZHAO D. Clinical outcomes of proximal gastrectomy versus total gastrectomy for locally advanced proximal gastric cancer: a propensity score matching analysis. Ann Oncol 2019; 30: ix52. https://doi.org/10.1093/ annonc/mdz422.025

[11] CHEN YC, LU L, FAN KH, WANG DH, FU WH. Proximal gastrectomy versus total gastrectomy for adenocarcinoma of the esophagogastric junction: A meta-analysis. J Comp Eff Res 2019; 8: 753-766. https://doi.org/10.2217/cer-2019-0016

[12] GOTO H, KANAJI S, OTSUBO D, OSHIKIRI T, YAMAMOTO M et al. Comparison of total versus subtotal gastrectomy for remnant gastric cancer. Langenbecks Arch Surg 2019; 404: 753-760. https://doi.org/10.1007/s00423-019-01821-x

[13] ZHAO L, LING R, MA F, REN H, ZHOU H et al. Clinical outcomes of proximal gastrectomy versus total gastrectomy for locally advanced proximal gastric cancer: A propensity score matching analysis. Transl Cancer Res 2020; 9: 27692779. https://doi.org/10.21037/tcr.2020.02.38

[14] OLMI S, GIORGI R, CIOFFI SPB, UCCELLI M, VILLA R et al. Total and Subtotal Laparoscopic Gastrectomy for the Treatment of Advanced Gastric Cancer: Morbidity and Oncological Outcomes. J Laparoendosc Adv Surg Tech A 2018; 28: 278-285. https://doi.org/10.1089/lap.2017.0372
[15] SOBIN LH, COMPTON CC. TNM seventh edition: what's new, what's changed: communication from the International Union Against Cancer and the American Joint Committee on Cancer. Cancer 2010; 116: 5336-5339. https://doi. org/10.1002/cncr.25537

[16] KATZ MH, editor. Study Design and Statistical Analysis A Practical Guide for Clinicians-Study Design and Statistical Analysis: A Practical Guide for Clinicians. Cambridge: Cambridge University Press 2006.

[17] SANTORO R, ETTORRE GM, SANTORO E. Subtotal gastrectomy for gastric cancer. World J Gastroenterol 2014; 20: 13667-13680. https://doi.org/10.3748/wjg.v20.i38.13667

[18] KONG L, YANG N, SHI L, ZHAO G, WANG M et al. Total versus subtotal gastrectomy for distal gastric cancer: Metaanalysis of randomized clinical trials. Onco Targets Ther 2016; 9: 6795-6800. https://doi.org/10.2147/OTT.S110828

[19] JU T, RIVAS L, KURLAND K, CHEN S, SPARKS A et al. National trends in total vs subtotal gastrectomy for middle and distal third gastric cancer. Am J Surg 2020; 219: 691-695. https://doi.org/10.1016/j.amjsurg.2019.04.012

[20] SABESAN A, PETRELLI NJ, BENNETT JJ. Outcomes of gastric cancer resections performed in a high volume community cancer center. Surg Oncol 2015; 24: 16-20. https:// doi.org/10.1016/j.suronc.2014.10.006

[21] QI J, ZHANG P, WANG Y, CHEN H, LI Y. Does total gastrectomy provide better outcomes than distal subtotal gastrectomy for distal gastric cancer? A systematic review and meta-analysis. PLoS One 2016; 11: e0165179. https://doi. org/10.1371/journal.pone.0165179

[22] NEVO Y, GOLDES Y, BARDA L, NADLER R, GUTMAN M et al. Risk factors for complications of total/subtotal gastrectomy for gastric cancer: Prospectively collected, based on the Clavien-Dindo classification system. Isr Med Assoc J 2018; 20: 277-280.

[23] CHEN K, ZHAI ST, PAN JH, YU WH, PAN Y et al. Shortterm outcomes of laparoscopic total gastrectomy for gastric cancer: a comparative study with laparoscopic distal gastrectomy at a high-volume center. Minim Invasive Ther Allied Technol 2018; 27: 164-170. https://doi.org/10.1080/1364570 6.2017 .1350718

[24] GERTSEN EC, BRENKMAN HJF, SEESING MFJ, GOENSE L, RUURDA JP et al. Introduction of minimally invasive surgery for distal and total gastrectomy: a population-based study. Eur J Surg Oncol 2019; 45: 403-409. https://doi. org/10.1016/j.ejso.2018.08.015

[25] WOO Y, SON T, SONG K, OKUMURA N, HU Y et al. A Novel Prediction Model of Prognosis After Gastrectomy for Gastric Carcinoma. Ann Surg 2016; 264: 114-120. https:// doi.org/10.1097/SLA.0000000000001523 